\title{
Đầu tư khoa học cho các trường danh giá có mang lại hiệu quả tốt hơn?
}

\author{
Hồ Mạnh Toàn \\ SSHPA System
}

Hà Nội, 15-11-2018

SSHPA (15-11-2018; Bổ sung, chỉnh lý từ bài SciComm: https://sc.sshpa.com/post/4327) - Hồi tháng 7 năm 2018, tác giả Wayne Wahls đã đăng tải một nghiên cứu nhỏ trên hệ thống bioRxiv đánh giá về tương quan giữa tiền tài trợ và đầu ra sản phẩm của các nghiên cứu y học nhận tài trợ từ quỹ United States National Institutes of Health (NIH) trong giai đoạn 2006-2015 [1].

Nghiên cứu đã chỉ ra các viện nghiên cứu thuộc nửa sau bảng xếp hạng 2016 US News \& World Best Medical Schools có số lượng công bố nhiều hơn 65\% và tác động về trích dẫn trên mỗi đô la tài trợ cũng cao hơn 35\% so với các trường/viện thuộc nửa trên (tức danh giá hơn) như Harvard Medical School, Stanford University, hay John Hopkins University. Mặc dù vậy, các ngôi trường danh giá có tỉ lệ nhận được tài trợ cao hơn đến $65 \%$ và tầm vóc các giải thưởng họ nhận được cũng lớn hơn 50\%.

\section{NIH grant productivity}

\section{Grants go further in less favoured institutions.}
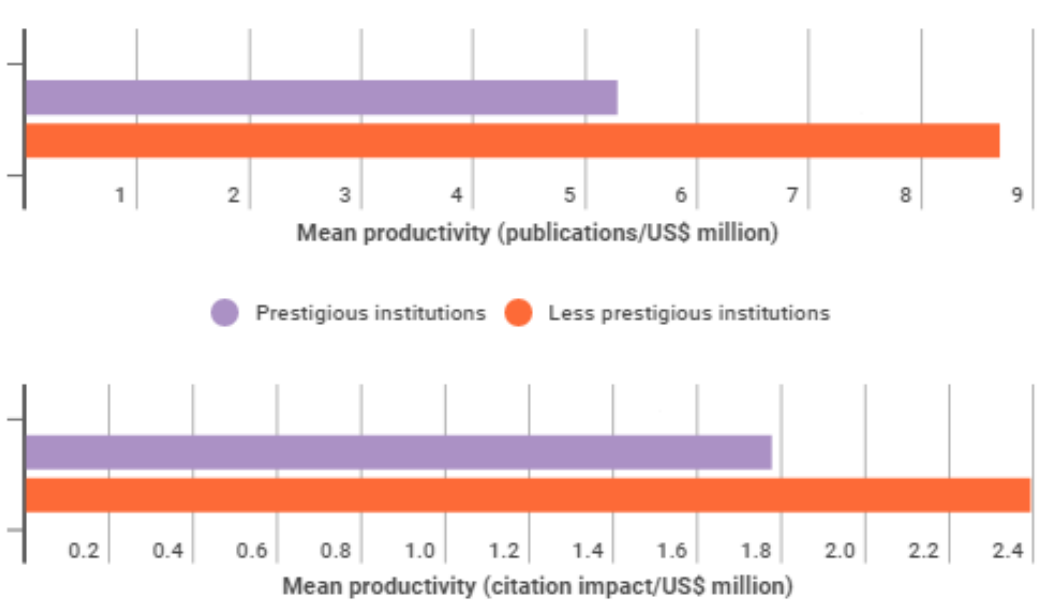

Prestigious institutions

Less prestigious institutions

Source: Wayne P. Wahls

(Nguồn: Nature Index từ Wayne P. Wahls) 
Tác giả Wayne Wahls đánh giá tồn tại sự thiên vị đáng kể đối với các trường đại học danh tiếng. Trên thực tế, lợi thế cho một vài cá nhân, tổ chức có 'hồ sơ đẹp' không phải là chuyện quá hiếm.

Tại Anh Quốc, phần đông sinh viên được Oxford chấp nhận đến từ top 20\% của xã hội [2]. Ở cấp độ cao hơn, một nghiên cứu hồi tháng 4 cũng chỉ ra rằng các nhà nghiên cứu sẽ nhận được nhiều tài trợ hơn và có khả năng trở thành giáo sư cao hơn nếu ngay từ gia đoạn sau tiến sĩ họ đã được nhận tài trợ nghiên cứu [3]. Tuy nhiên, ảnh hưởng không nhỏ của vấn đề này đến từ việc các nhà nghiên cứu sau khi bị loại khỏi cuộc đua nhận tiền tài trợ cũng giảm nhuệ khí và nộp hồ sơ xin tài trợ ít hơn.

Có thể thấy, dù có nhiều nguyên nhân khác nhau nhưng việc sở hữu danh tiếng tốt mang lại lợi ích đáng kể cho cả cá nhân nhà nghiên cứu và các trường đại học. Người phát ngôn của $\mathrm{NIH}$ cho biết các đánh giá từ cộng đồng nghiên cứu này là rất quan trọng và cần thiết để đảm bảo cũng như cải thiện hiệu quả trong đầu tư khoa học [4]. Tuy nhiên, cũng có một số nhà khoa học khác cho rằng nên cẩn trọng với việc đánh giá chỉ dựa trên 'hệ số thu nhập trên đầu tư'.

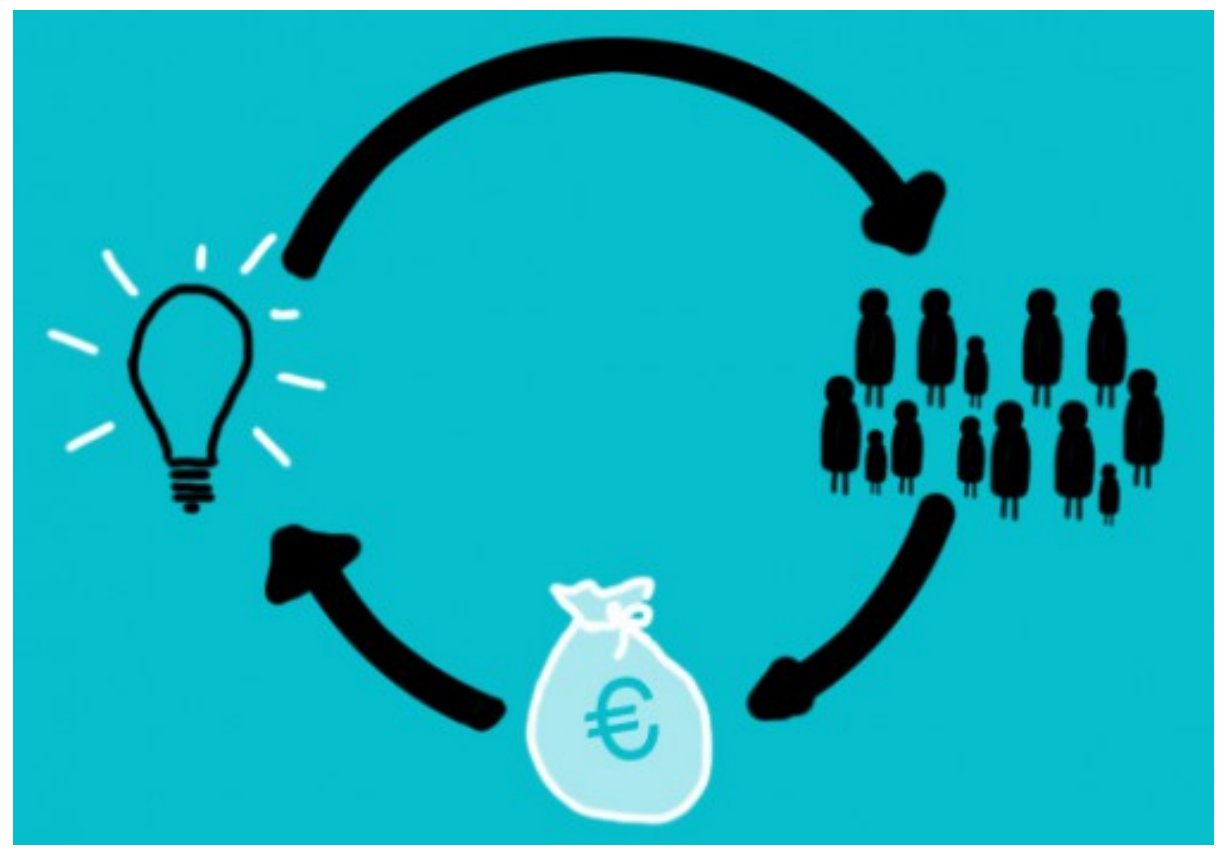

(Nguî̀n: SIRIS Academic)

Đối với các quỹ tài trợ tại Việt Nam như NAFOSTED, đây là một yếu tố rất đáng lưu tâm để vừa đảm bảo tính công bằng, hợp lý của tài trợ khoa học lại vừa có thể thúc đẩy chất lượng khoa học. Bất chấp quan niệm đặt kẻ 'sĩ' lên đầu trong truyền thống đạo Khổng lâu đời của mình [5], Việt Nam vẫn là một nước đang phát triển và phải vào đường đua với thế giới để đảm bảo sự ổn định của đất nước, trong khi cùng lúc đối diện với chất lượng giáo dục và nghiên cứu. Chính vì thế, hiệu quả đầu tư khoa học là một câu hỏi thường xuyên được đặt ra khi các vấn đề của nền giáo dục như chất lượng đào tạo, hay thi cử vẫn còn rất ngổn ngang [6]. 
May mắn là sự phân biệt chất lượng và danh giá tại các trường đại học Việt Nam là chưa tạo thành khoảng cách quá lớn. Chính vì thế, việc đảm bảo sự phân bố tài trợ phù hợp và kích thích năng lượng cũng như năng suất của các nhà nghiên cứu, các viện nghiên cứu khoa học tại Việt Nam hoàn toàn có cơ hội trở thành hiện thực hiện, nếu có chính sách và kế hoạch tốt, kết hợp với năng lực quản lí tài nguyên.

\section{References:}

[1] Wahls, W. P. (2018). High cost of bias: Diminishing marginal returns on NIH grant funding to institutions. bioRxiv, 367847; doi: 10.1101/367847. Truy cập từ URL: https://www.biorxiv.org/content/early/2018/07/13/367847

[2] Rusbridger, A. (2018). If Oxford shrugs. Prospect Magazine. Retrieved from https://www.prospectmagazine.co.uk/magazine/if-oxford-shrugs-alan-rusbridgeradmissions-Imh.

[3] Bol, T., de Vaan, M., \& van de Rijt, A. (2018). The Matthew effect in science funding. Proceedings of the National Academy of Sciences, 115(19), 4887-4890, DOI: 10.1073/pnas.1719557115.

[4] Armitage, C. (2018). Less prestigious institutions deliver better value for grant money. Nature Index. Retrieved from https://www.natureindex.com/news-blog/less-prestigiousinstitutions-deliver-better-value-for-grant-money.

[5] Vuong Q. H., Tran T. D. (2009). The cultural dimensions of the Vietnamese private entrepreneurship. IUP Journal of Entrepreneurship Development, VI(3-4): 54-78.

[6] Vuong, Q. H. (2018). The (ir)rational consideration of the cost of science in transition economies. Nature Human Behaviour 2(1): 5, DOI: https://doi.org/10.1038/s41562-0170281-4. URL: https://www.nature.com/articles/s41562-017-0281-4. 